\title{
Acute stroke trials: the elephant in the room
}

\author{
Mayank Goyal
}

Received: 5 March 2013 / Accepted: 16 April 2013 / Published online: 5 May 2013

(C) Springer-Verlag Berlin Heidelberg 2013

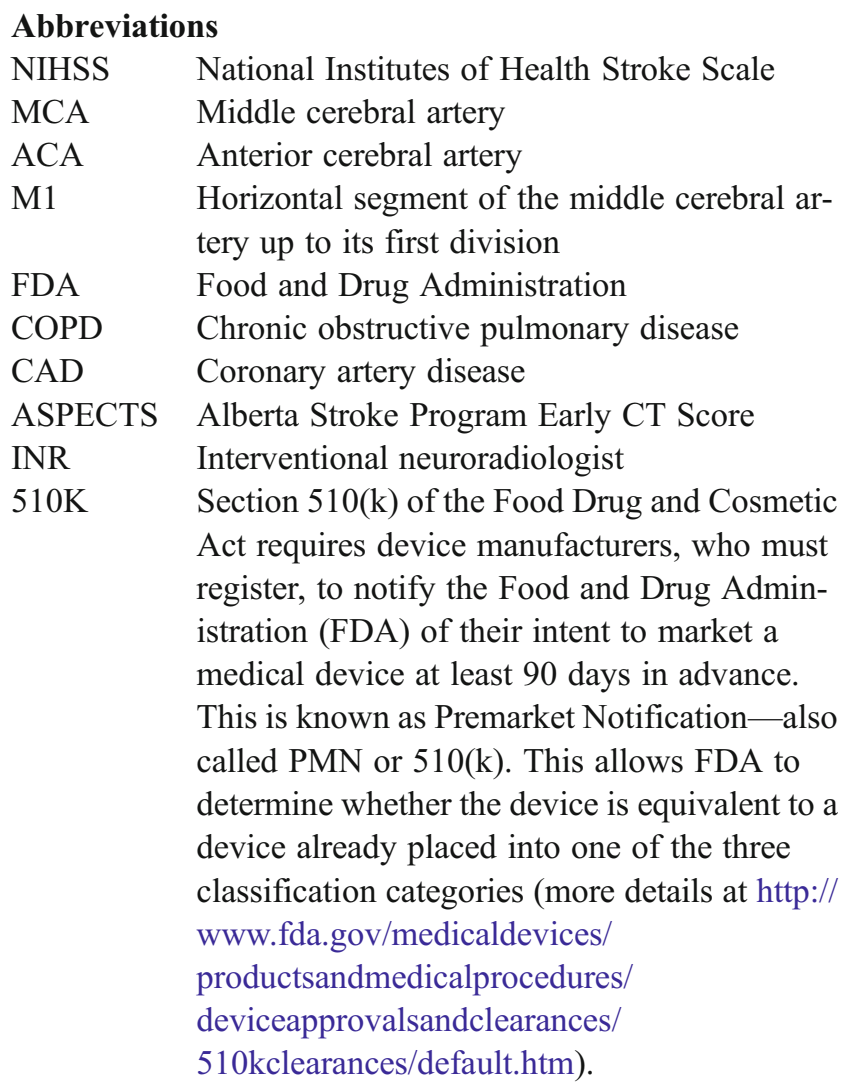

The following are based on true stories (either from personal experience or conversations with colleagues at meetings).

\section{Scenario 1}

A 65-year-old otherwise healthy female patient presents with large left middle cerebral artery (MCA) stroke $80 \mathrm{~min}$

\section{Goyal $(\bowtie)$}

Department of Radiology, Foothills Medical Centre, University of

Calgary, 1403 29th St. NW,

Calgary, Alberta T2N 2T9, Canada

e-mail: mayank.goyal@calgaryhealthregion.ca from onset and a National Institutes of Health Stroke Scale (NIHSS) of 21. Imaging shows a small core and occlusion in the M1 segment of the left middle cerebral artery.

Stroke neurologist (to patient's son who is well educated, works as an accountant): Your mother is having a severe stroke due to blockage in one of the large vessels in her brain. This requires urgent intervention to give her the best chance of recovery. We are going to be starting her on a clot busting drug called tPA. However, we are also part of a randomized trial, to test a new therapy.

Patient's son: What is the new therapy?

Stroke neurologist: Your mother would be taken to the cath lab where a small tube would be advanced to the vessels of the brain under X-ray guidance similar to what is done for a heart attack. Once it is in position, we would try and suck the clot out to reestablish flow to the brain. This procedure, however, is not a wellestablished procedure and does carry a risk. If you choose to participate in the trial, there is a $66 \%$ chance that your mother will go to the cath lab. Of course, there is a one-third chance that she won't in which case, she would receive the intravenous clot busting drug and be shifted to the stroke unit.

Patient's son: How is she doing now?

Stroke neurologist: There has been no change in her status so far.

Patient's son: What would you do if I refuse to participate in the trial?

Stroke neurologist (hesitantly...): We would take her to the cath lab.

Patient's son: In that case, we don't want to participate in the trial.

Questions

1. Why do patients and their relatives find the idea of the "cath lab" attractive even though it is unproven and carries risk? 
2. How should the physician answer the question of what would be done if the patient refused to participate in the trial? Should the answer be no, we won't take to cath lab (even though the physician feels that to be the most appropriate thing to do)?

\section{Scenario 2}

A 42-year-old single mom with two kids aged 14 and 11 otherwise healthy presents with large right MCA stroke 100 min from onset and a NIHSS of 18. Imaging shows a small core and right M1 occlusion.

Interventional neuroradiologist (to stroke neurologist on the phone): I am getting the cath lab ready. How long would it take to move her there?

Stroke neurologist: Hang on. Not so fast. I am going to discuss the trial with them and see which side she gets randomized.

Interventional neuroradiologist (INR): Are you crazy? Clearly she needs to go to cath lab. There is no equipoise here.

Stroke neurologist: Of course, there is. Show me some good data to show that your IA therapy is going to be better than standard of care.

INR (almost shouting): Absence of evidence is not evidence of absence. What if this was your sister? What would you do then?

By this time, other stroke neurologists and INR join in the discussion. There are lots of strong feelings and lots of argument. Time is ticking by...patient finally goes for endovascular treatment and does not participate in the trial.

\section{Questions}

1. Is equipoise generic or are certain situations such as younger age groups exempt from the trial because we, as a community, already know the answer?

2. If yes, are we able to convince the powers to be (FDA, etc.) to approve the procedure for those situations without a trial?

3. If we are not able to convince them, do we have an obligation to randomize them in trials in spite of what we believe in?

\section{Scenario 3}

An 81-year-old patient presents to the hospital at 0700 hours with a large left MCA syndrome 75 min from onset, a NIHSS of 16, and previous history of COPD and CAD with previous coronary stenting. Imaging shows Alberta Stroke Program Early CT Score (ASPECTS) of 6, ICA + M1 occlusion, and large penumbra involving MCA and ACA territories.

Stroke neurologist (to INR on the phone): Just to give you a heads-up. There is a patient in ER with....

INR (sitting with his son at hockey practice watching the game): Why don't you go ahead and randomize and call me back if it gets randomized in the IA arm. Stroke neurologist: The trial nurse is not answering her pager. Why don't we take him to angio anyway? INR: Why don't we wait for a few minutes. After all, it is important to put patients in trials.

Stroke neurologist: OK. But in the meantime, why don't you come to the hospital and call your team in. INR (reluctantly): OK. We'll be there as soon as we can but please be sure to let me know if patient gets randomized to IV only. By the way, what is the arch like? Is it even doable?

Stroke neurologist: Come on, since when have you started worrying about this? Anyway, see you soon.

INR (to his wife, after putting the phone down): Dear, can you come to the hockey arena. I have to go in.

Wife: OK, I'll be there in around 25 minutes....

Patient gets randomized to intra-arterial (IA) therapy. The time from start of IV to groin puncture was $145 \mathrm{~min}$.

\section{Questions}

1. Does the overall circumstance influence the efficiency of care?

2. Does this lack of efficiency selectively affect one arm?

\section{Scenario 4}

A 58-year-old otherwise healthy man presents with aphasia, right-sided weakness, and a NIHSS of 12, $90 \mathrm{~min}$ from onset. He is brought over by ambulance. There is no family with him. Imaging shows ASPECTS of 8, left M1 occlusion, and sizeable penumbra. Patient is started on IV tPA. The team wants to randomize the patient. It is now 0825 hours. However, there is no one to give consent. Paramedics say that family is on the way.

Stroke neurologist (to paramedic): Why didn't you get the family member along?

Paramedic: We are not allowed to. 
Stroke neurologist: Do you have a cell phone number for her?

Paramedic: I don't, but my colleague does. Let me get it.

He comes back at 0845 hours with the phone number. Stroke neurologist dials the number. A female voice answers.

Stroke neurologist: Hi! I am Dr.... wondering how far you are from the hospital?

Person at other end: I am in the hospital looking for parking.

Stroke neurologist: Can you please come in to ER as soon as you can?

Patient's family member shows up at 0900 hours. Stroke neurologist explains the trial. Now it is 0915 hours.

Patient's family member: I have known him only for 10 months. I don't think I can take this complex decision. I think, I should involve his ex-wife in the decision-making process. Let me give her a call.

Stroke neurologist: OK.

At 0930 hours, patient's ex-wife to stroke neurologist on the phone: I don't fully understand what you are saying. Maybe I should come into the hospital.

Stroke neurologist (exasperated): I don't think we have time for that. Brain cells are dying, you know and we do need to treat this urgently.

Ex-wife: I am not sure if I am the right person to make this decision. Can I talk to his significant other?

The two women are on the phone. Finally at 0955 hours, they say: OK we are fine to go ahead with the trial.

The patient gets randomized to the IA arm and is taken to angio, and recanalization is achieved at 1145 hours.

\section{Questions}

1. Is there a way to simplify the consent process for a very complex, urgent situation wherein the family is emotionally charged, suffering from information overload and likely to be in "analysis paralysis"?

\section{Responses}

Here are some of the responses that I got.

Dr. Worrier: IMS3 [1] and MR RESCUE [2] were futile. What will happen now? Already carotid stenting and intracranial stenting trials were negative. There will be no support to do IA therapy for acute stroke. How will
I find a job at the end of the fellowship? A recent article in JNIS is calling for stopping neurointervention fellowships [3]. We should do something to make sure that IA therapy is protected.

Dr. Warrior: Who said it was going to be easy? This is how real life is. We have to work together to work on solutions, achieve consensus, create systems that protect in the interests of the individual patient, allow freedom of decision making, promote innovation but still allow for practice of evidence-based medicine. Dr. Trialz Arking: We should stop all IA therapy outside of trials. There will be no way to patient to get to the angio suite unless they are part of the trial. In fact, the whole $510 \mathrm{~K}$ process is flawed. We should get rid of that process altogether.

Dr. Xperienz: I have been practicing for 23 years. I know what is best for my patients. RCTs can never solve the problem. Each patient is different and complex. I have to do what is in the best interest of my patient.

Of note, none of the people gave any real, practical answers. There has been a lot of talk in recent meetings regarding the futility of IMS3. I have heard several people talk about (1) lack of sophisticated imaging in the trial and (2) lack of modern recanalization devices [4]. I wonder whether the questions raised above are more important for the success of future trials.

Conflict of interest I declare that I have no conflict of interest.

\section{References}

1. Broderick JP, Palesch YY, Demchuk AM, Yeatts SD, Khatri P, Hill MD, Jauch EC, Jovin TG, Yan B, Silver FL, von Kummer R, Molina CA, Demaerschalk BM, Budzik R, Clark WM, Zaidat OO, Malisch TW, Goyal M, Schonewille WJ, Mazighi M, Engelter ST, Anderson C, Spilker J, Carrozzella J, Ryckborst KJ, Janis LS, Martin RH, Foster LD, Tomsick TA, the Interventional Management of Stroke (IMS) III Investigators (2013) Endovascular therapy after intravenous t-PA versus t-PA alone for stroke. N Engl J Med 368:893-903

2. Kidwell CS, Jahan R, Gornbein J, Alger JR, Nenov V, Ajani Z, Feng L, Meyer BC, Olson S, Schwamm LH, Yoo AJ, Marshall RS, Meyers PM, Yavagal DR, Wintermark M, Guzy J, Starkman S, Saver JL, MR RESCUE Investigators (2013) A trial of imaging selection and endovascular treatment for ischemic stroke. N Engl J Med 368:914-923

3. Fiorella D, Hirsch JA, Woo HH, Rasmussen PA, Shazam Hussain M, Hui FK, Frei D, Meyers PM, Jabbour P, Gonzalez LF, Mocco J, Turk A, Turner RD, Arthur AS, Gupta R, Cloft HJ (2012) Should neurointerventional fellowship training be suspended indefinitely? J Neurointerv Surg 4:315-318

4. Zaidat OO, Lazzaro MA, Gupta R, Yavagal DR, Rasmussen PA, Hirsch JA, Castonguay AC, Tarr RW (2012) Interventional management of stroke III trial: establishing the foundation. J Neurointerv Surg 4:235-237 